\title{
Aphally and imposex in Nucella lapillus from Galicia (NW Spain): incidence, geographical distribution and consequences for the biomonitoring of TBT contamination
}

\author{
R. Barreiro*, M. Quintela. J. M. Ruiz \\ Depto. Biología Animal, Biología Vegetal y Ecología, Universidade da Coruña, Campus da Zapateira s/n, \\ E-15071 A Coruña, Spain
}

\begin{abstract}
Males of Nucella lapillus (L.), an intertidal gastropod, can suffer from a curious genetic disorder that causes underdevelopment of the reproductive tract ('Dumpton Syndrome' [DS]). Its extreme form leads to a lack of a penis ('aphally') and an incompletely developed vas deferens (VD) DS-affected females are also recognisable by a lesser degree of masculinisation ('imposex') when exposed to tributyltin (TBT) pollution, i.e. penis development may be lacking (female 'aphally') and VD formation may be weak. Based on the results of an extensive survey (at 56 stations) around Galicia (NW Spain) from 1996 to 1998, it is now known that imposex is widespread and the variations shown in its development indicate that DS also occurs widely. A modified version of the Vas Deferens Sequence (VDS) schemes currently devoted to assess the intensity of masculinization of female $N$. lapillus is proposed. It attempts to accommodate the variants in imposex development observed in a DS-affected population whilst remaining both simple and comparable with previously applied schemes. The proposed VDS classification solely employs VD development as a ranking criterion so as to attain a consistent scoring of both aphallic and penis-bearing females. Importantly, the evidence indicates aphally need not preclude a female from being sterilized. Both males and females afflicted by DS were scattered throughout the Galician region, although aphallic females were present at many sites at which DS males went unrecorded. Also, female aphally was commonly more frequent than male aphally on a per site basis. DS-affected males were very uncommon, never exceeding $\sim 20 \%$ and more frequently constituted $<10 \%$. In contrast, aphallic females were common, reaching frequencies of 20 to $50 \%$ at some sites, although overall it also must be considered a low-frequency phenomenon. Imposex levels, overwhelmingly dominated by VDS Stage 4, showed that TBT pollution is widespread throughout the region. However, a high degree of inter-individual variability was found at many locations. At those sites, females showing no signs of imposex or only an early stage (i.e. VDS Stages 0 to 2) were found thriving alongside heavily afflicted individuals (VDS Stages 4 to 6 ). The significant association between this variability in the effects of imposex and the presence of DS strongly reinforces the interpretation of DS as a genetic disorder which lessens the effects of TBT The consequences those TBT-resistant specimens might have for the impact of TBT on the population level are discussed as well as the impact their presence might pose for the assessment of TBT pollution and its effects based on imposex indices currently in use.
\end{abstract}

KEY WORDS: Imposex $\cdot$ Nucella lapillus $\cdot$ Dumpton Syndrome $\cdot$ TBT $\cdot$ Pollution resistance $\cdot$ Aphally NW Spain

\section{INTRODUCTION}

Present evidence indicates that imposex in marine gastropods (i.e. the imposition of male sex organs on

·E-mail: rodbar@udc.es females) occurs not just on a regional scale, but is a widespread phenomenon (see Bryan \& Gibbs 1991, Gibbs \& Bryan 1996). Both laboratory and field studies have consistently linked this morphological aberration to tributyltin (TBT) contamination (e.g. Bryan et al. 1987, 1988, Gibbs et al. 1988, Oehlmann \& Bettin 1996, Mensink et al. 1997, Oberdörster et al. 1998); and to 
date, over 50 neogastropod species worldwide have been shown to exhibit imposex, although a strong link to TBT exposure has been established in only a few of them (Gibbs et al. 1997). The pandemic character of the imposex is thus impressive.

The sensitivity to TBT pollution greatly differs among species. In this regard, the common European neogastropod Nucella lapillus (L.) combines a thorough scientific background on its imposex response together with the dubious honour of being among those species most sensitive to the detrimental effects of TBT. Several studies have focused on assessing the intensity of TBT effects and their geographical scale employing imposex in $N$. lapillus as a sensitive biomarker (for a review on the use of the imposex response in biomonitoring surveys, see Gibbs \& Bryan 1994). In fact, imposex in $N$. lapillus is one of the biological effects recommended to implement the OSPAR guidelines on TBT-specific monitoring (see QUASIMEME Scientific Assessment Group 1998).

A remarkable conclusion from previous studies made along the Atlantic European coasts is the considerable variability observed in the morphological expression of imposex in Nucella lapillus (e.g. Oehlmann et al. 1991). Some effort has been devoted to design a classification system able to deal with that variability (Fioroni et al. 1991)-but, it is surprising that, the acknowledgement of such variation has not stimulated a more thorough re-examination of the potential for inter-individual differences in the sensitivity to TBT linked to the different paths of imposex development already identified.

We know now that some populations have survived higher exposures to TBT contamination through a lessened expression of imposex; the striking example being the discovery of a small enclave of surviving dog-whelks on the coast of Kent, SE England, in a region (Strait of the Dover-Thames Estuary) where TBT had eliminated all populations of the species. Significantly, this enclave contained males exhibiting an unusual defect (a genetic deficiency) involving the non-development, or partial development, of the genital system: about $10 \%$ lack penes, or have undersized penes, and their gonoducts (vas deferens and prostate) are incompletely developed. This is Dumpton Syndrome. Given the axiom that imposex is a faithful transfer of male characters to the female, it follows that underdevelopment of male genitalia will result in the same abnormality being manifest when imposed on the female. Hence, the sterilising influence of imposex is lessened in carrier females (evidenced by lower Vas Deferens Sequence [VDS] stages) and these are able to continue breeding with non-carrier males, ensuring survival of the population (see Gibbs 1993). Later, the same phenomenon has been identified around, and in, the Bay of Brest, NW Brittany on the other side of the English Channel (Huet et al. 1996). Perhaps the apparently restricted geographical range of these TBT-resistant specimens has partly masked the relevance of their presence within dog-whelk populations.

In this paper we present the results of an extensive survey performed in NW Spain showing that TBTresistant specimens of Nucella lapillus are more widely distributed than previously thought. We also discuss some of the classification schemes currently in use for the quantitative assessment of imposex intensitysince none of them satisfactorily fit our observations. Finally, we highlight the considerable amount of interindividual variation in the sensitivity to TBT that can be observed in some $N$. lapillus populations, stressing the interference such variability might pose for the uninformed use of this species in biomonitoring programs.

\section{MATERIALS AND METHODS}

Collection of study animals. Data are based on surveys carried out from July 1996 to May 1998. Most samples were collected within rias, estuaries formed by drowned river valleys. Having their water renewal partly restricted and suffering from high levels of human activity on their shores and waters, it is within these rias where the highest levels of pollutants are expected. Nevertheless, even those sites located outside these rias are exposed to pollutants, such as organotins, in amounts high enough to affect their Nucella lapillus populations (Ruiz et al. 1998). Samples consisted of at least 30 adult $N$. lapillus collected from 56 locations throughout the coastline of Galicia (Fig. 1, Universal Transverse Mercator co-ordinates in Table 1). Most places were visited in the summer of 1996 (July-September, 34 locations); additional locations were sampled in autumn-winter of 1996 (October 1996-January 1997, 11 locations) and in winterspring of 1998 (December 1997-June 1998, 11 locations). Locations $1,10,13$ and 50 were repeatedly sampled during 1997, and their data pooled for easiness. Sampling size was also increased for some selected localities (Sites 11, 14, 36, 37, 40, 41, 51, and 52), re-sampling them in May 1998 when at least 100 adult snails were collected at each site.

Imposex assessment. Specimens were examined following procedures given by Gibbs et al. (1987). Before breaking the shell with a vice, shell and aperture lengths were measured to the nearest $0.01 \mathrm{~mm}$ with a digital calliper. Thereafter, individuals were sexed, dissected, and studied under a stereo microscope. Specimens parasitised were excluded from further 
Table 1. Nucella lapillus. Aphally and imposex in Galician populations 1996 to 98 . Total number of males and females including sampling Stn no. and Universal Transverse Mercator co-ordinates (UTM). Females are classified according to the Vas Deferens Sequence (VDS) series of stages; numbers in square brackets indicate Stage 3 to 5 females lacking a penis (3-5NP) and non penisbearing males (NP). Stations grouped by main rias when applicable; sites located outside rias are grouped under North coast and West coast titles. Stations with both aphallic females and low imposex stages (i.e. 0 to 2) moderately frequent are framed; stations with aphallic males in bold

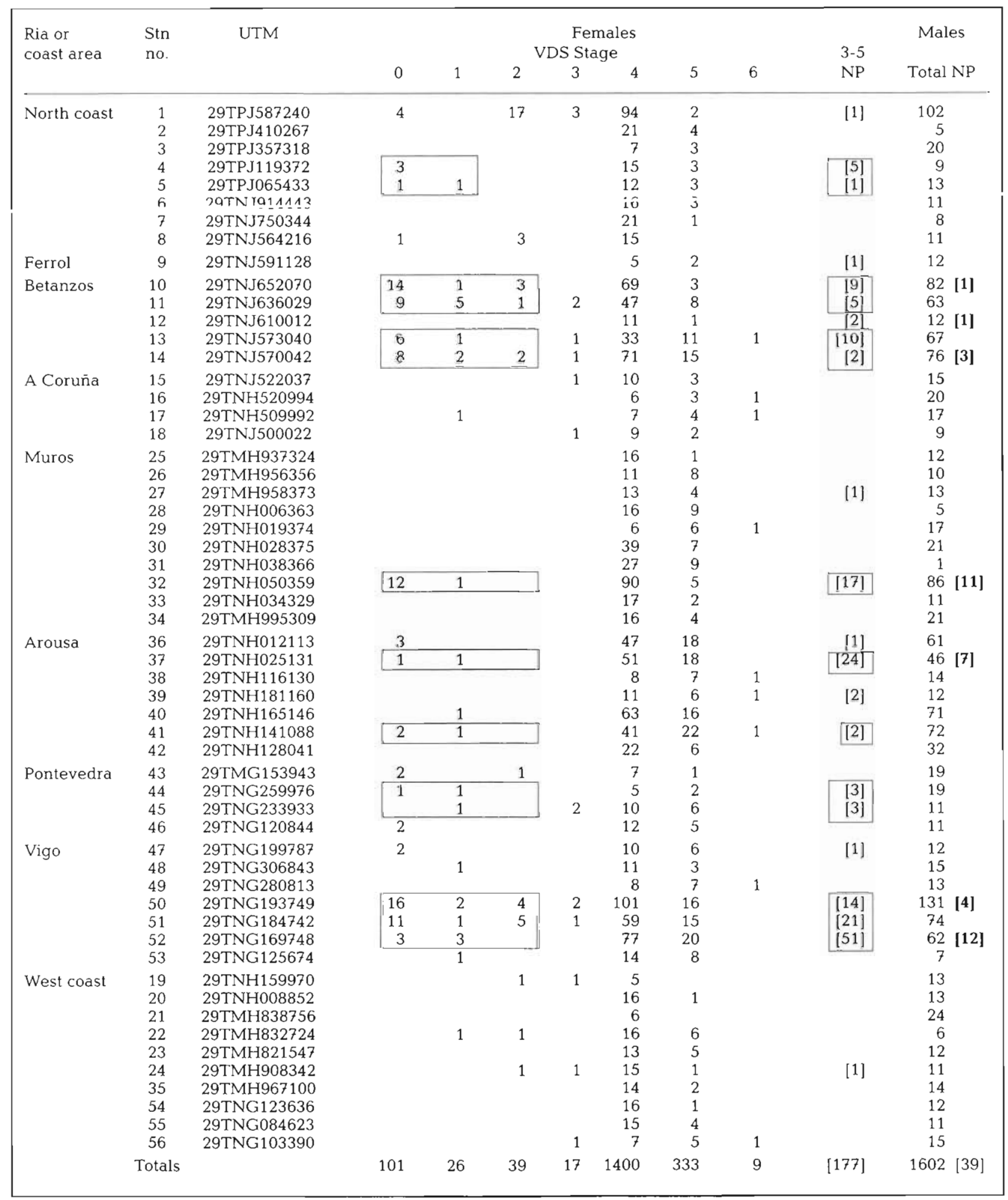


analyses. Penis lengths were measured to the nearest $0.01 \mathrm{~mm}$ in their natural position using a digital calliper.

A Vas Deferens Sequence Index (VDSI) was determined for each female by close examination of its genitalia. The original VDS scheme proposed by Gibbs et al. (1987) had to be slightly redefined to account for the numerous 'aphallic' females present among Galician populations (see 'Discussion' section and Fig. 2). VDS Stages 0 and 1 remain as originally defined. A VDS of 2 was assigned to females with a VD whose total length was less than one third the distance between the genital papilla and the base of the right tentacle, where the penis eventually develops. It usually consisted of 2 unconnected sections: proximal and distal (in specimens capable of developing a penis the distal structure is in fact part of the penial duct). A VDS of 3 was ascribed to females bearing an incomplete VD, whose total length stretched more than one third the distance between the area behind the right tentacle and the vaginal opening; it usually consisted of 2 unfused sections. VDS Stage 4 corresponded to females with a VD entirely developed, i.e. a single duct from the area behind the right tentacle to the genital papilla. Those females with the vaginal opening displaced, constricted or overgrown by the proximal section of the VD were assigned a 5 . Finally, Stage 6 was assigned to snails whose capsule gland.

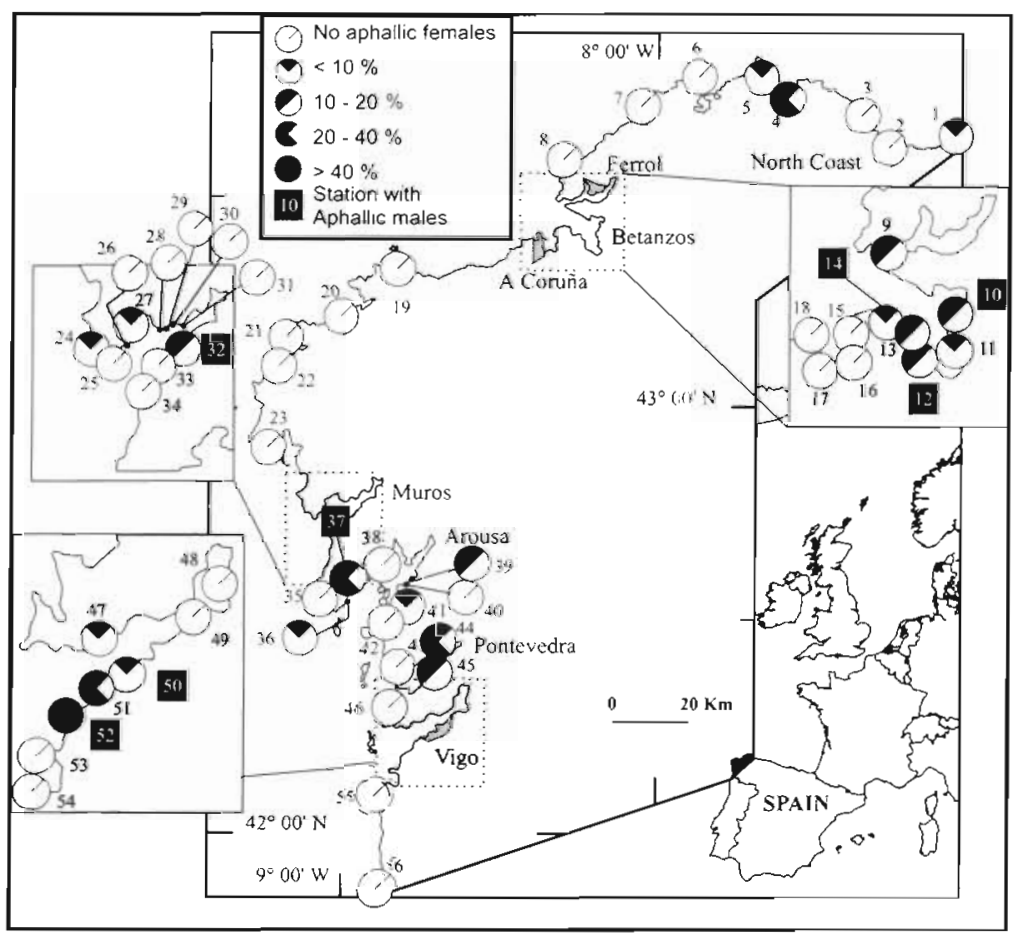

Fig. 1. Nucella lapillus. Positions of sampling stations in Galicia (NW Spain), distribution and frequency of female aphally, and distribution of male aphally contained the material of aborted capsules. As in the original scheme, specimens ascribed to Stage 5 or greater have their reproductive ability impaired and are subsequently termed sterile females. Females assigned to Stages 3 to 5 could either bear a penis, or lack it; the later are termed 'aphallic' females hereafter, i.e. females with a well-developed VD that lack a penis. To date, just a few individuals have been recorded as belonging to Stage 6 and none of them lacked a penis.

\section{RESULTS}

\section{Male and female aphally}

Only 39 out of a total of 1602 males $(2.4 \%)$ were aphallic (Table 1); these were scattered throughout 4 different rias ( 7 of the 56 sampling locations) instead of concentrated in a single area. Within these locations, aphallic males were still scarce. At 4 stations (Stns 10, 12,14 , and 50) only a few individuals, representing frequencies $<10 \%$ of males, were collected per site. Male aphally reached higher values (>12\%) at 3 sites (Stns 32, 37, and 52), each one located within a different ria, but even at these sites aphally never surpassed $-20 \%$ of males. As described by Gibbs (1.993) for the Dumpton population, aphallic males not only had failed to develop a penis but also displayed symptoms of a broader underdevelopment of the genital tract, specifically a split prostate recognisable by the brownish colouring of its unfused edges.

Occasionally, a few males bearing undersized penes were collected 3 from Stn 13, 2 from Stn 50, 1 from Stn 5, 1 from Stn 12). Since these individuals were very scarce, penis-length distributions remained mostly unaffected by their presence. In fact, ranges of penis lengths in samples from populations affected by male aphally, after aphallic males were excluded, were usually indistinguishable from those estimated for sites at which neither male nor female aphally were found. Fig. 3 is an example of male penis-length distributions in samples from different populations: the range of penis lengths where male aphally was abundant (e.g. Stn 52) is similar to that recorded for a site with no aphallic individual ever found (e.g. Stn 40). Seldom did some samples from aphally-affected populations result in ranges wider than usual. 

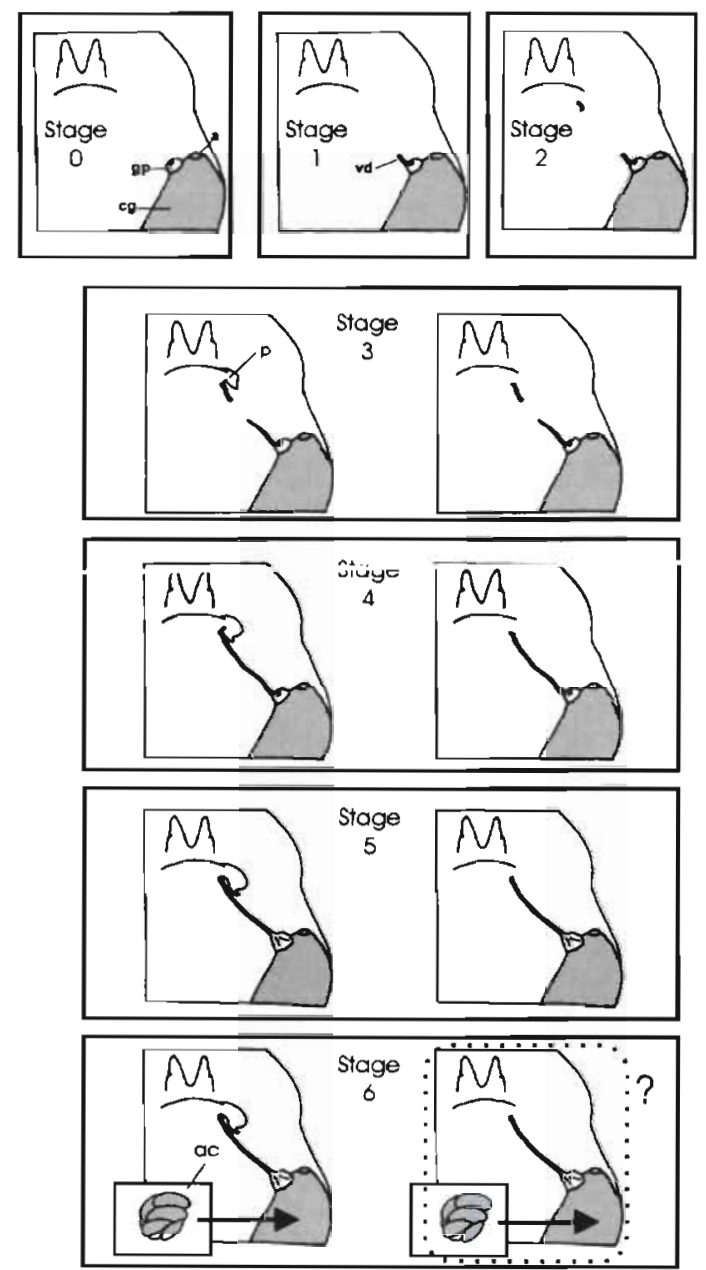

Fig. 2. Aphally and imposex in Nucella lapillus. Proposed modification of the Vas Deferens Sequence (VDS) scoring system based solely on VD development. Starting at Stage 3, both penis-bearing and aphallic specimens are distinguished. Aphallic Stage 6 is depicted only as feasible. See 'Materials and methods' for explanation. $\mathrm{a}=$ anus; $\mathrm{ac}=$ aborted capsules; $\mathrm{cg}=$ capsule gland; $\mathrm{gp}=$ genital papilla; $\mathrm{p}=$ penis; $\mathrm{vd}=$ vas deferens

Unlike males, female aphally was widespread throughout the region (22 of the 56 stations). No clear pattern could be depicted, although rias such as Betanzos ( 5 out of 5 sites), Arousa ( 4 out of 7 sites) and to a lesser extent Vigo (4 out of 7 sites) did concentrate higher frequencies of sampling locations suffering from female aphally. On the contrary, aphallic females went unnoticed within A Coruña (4 sites). Female aphally was regularly more frequent than male aphally on a per site basis. Yet, it still remained mostly a rather scarce event since 10 sites had $<10 \%$ of their females affected. However, 20 to $40 \%$ of females were aphallic at 4 sites (Stns 4, 37, 44 and 51) and even a frequency of $49.5 \%$ (51 out of 103 females) was estimated for Stn
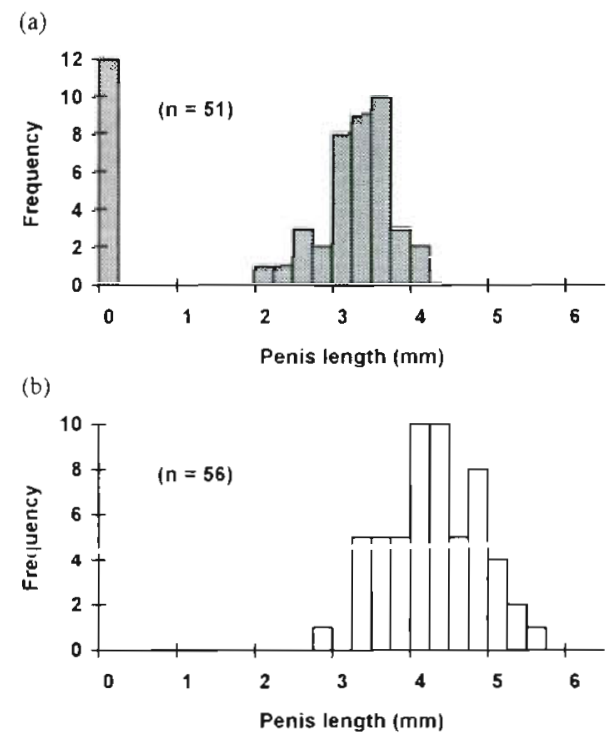

Fig. 3. Aphally and imposex in Nucella lapillus. Frequency (number of individuals) of penis length in males from (a) Stn 52 at which male and female aphally have been recorded, and (b) Stn 40 at which no aphally has been found

52. Female aphally was detected at many sites at which aphallic males went unrecorded while male aphally was recorded only at sites with aphallic females.

\section{Imposex}

All but 3 stations (Stns 8, 19, and 21) contained some sterile females, denoting that TBT pollution was widespread throughout the region. As expected, sites less affected by imposex were located outside the rias. For the most part, sterile females ranged from 10 to $30 \%$ (30 stations); still 13 stations surpassed these values, and 3 sites (Stns 29, 38, 49) even reached $\sim 50 \%$.

A VDS stage of 4 was overwhelmingly predominant (72.7\% of females), followed far-off by Stage 5 (17.3\% of females). Nevertheless, it was somewhat unexpected to find out that females with no imposex or only an early one (VDS Stages 0 to 2) were coexisting along with unmistakably afflicted ones (VDS Stages 4 to 6) at some stations. That was the case for most sampling sites within the rias of Betanzos (Stns 10, 11, 13, and 14) and Pontevedra (Stns 43,44,45, and 46), some stations on the southern bank of the ria of Vigo (Stns 50 , 51 and 52) and others scattered throughout the ria of Arousa (Stns 36, 37, and 41). Thus, at those stations females seemed divided into 2 groups of imposex status rather than gathered into a homogeneous population of VDS stages. 


\section{DISCUSSION}

\section{Dumpton Syndrome and male aphally}

\section{Distribution}

According to Gibbs \& Bryan (1996), no published record of male aphally in neogastropods existed until Gibbs (1993) recorded the discovery of some specimens of Nucella lapillus in an enclave at Dumpton Gap (SE England). That genital deficiency was termed 'Dumpton Syndrome' (DS), apparently being an inheritable disorder. Up to now, DS seemed confined to some enclaves on both ends of the English Channel (Dumpton Gap in SE England, and Brest in NW France) (Gibbs 1993, Huet et al. 1996). However, aphallic males found in Galician populations undoubtedly suffer from the same genital defect; not only in both cases do males lack penes but they also show a similar underdevelopment of the gonoduct, manifest by the diagnostic character of DS in the prostate being unfused, giving it a split structure. Thus considered, our finding abruptly widens the geographic range of DS along the Atlantic European coasts; DS is also found some $5^{\circ}$ of latitude south of Brest or, what is more relevant for an intertidal snail, some thousand kilometres of coast apart. The isolation of Galicia populations from northerner congeners might be even more extreme given the scarcity of this species on most shores of the Bay of Biscay.

A puzzling aspect of DS males in Galicia is their scattered distribution. These individuals have been found

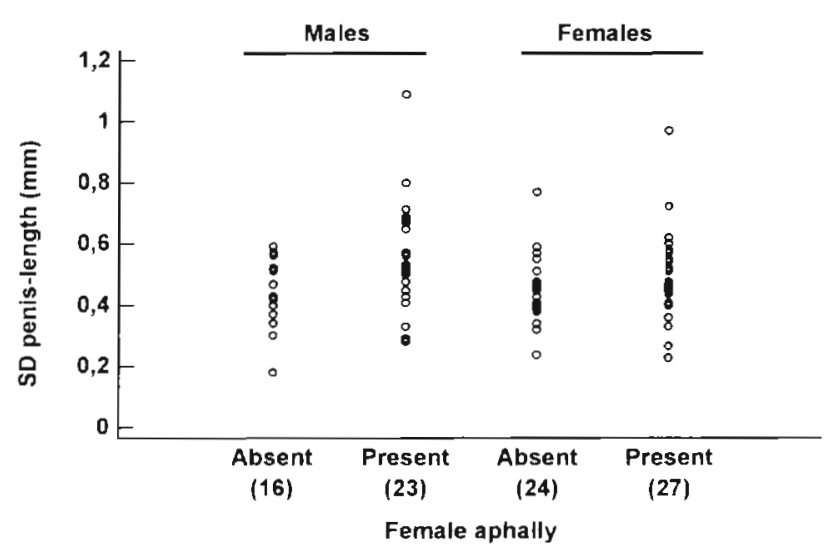

Fig. 4. Aphally and imposex in Nucella lapillus. Variability of penis lengths compared between stations at which female aphally was recorded, and those at which it went unnoticed. Each point represents the standard deviation (SD) of penis lengths in a sample after aphallic individuals were excluded: number in parentheses are total number of samples per group; only samples with more than 15 specimens included (males per sample: 15 to 61 ; females: 15 to 66 ). When a station was sampled on several dates, an SD was estimated for each sampling event in different rias, some of them (e.g. Betanzos) separated by many kilometres of coast at which both male and female aphally have gone totally unnoticed. Partly based on the geographic distance between Brest and Dumpton, it has been hypothesised that the DS observed at these 2 locations might be due to 2 different mutations (Huet et al. 1996). Following the same reasoning, we would have to propose the existence of additional mutations to account for the various DSaffected populations found at Galicia, confronting us with several mutations which have resulted in the same morphological deformity. Instead, we think it might be easier to accept that the same DS genotype was already present in these Nucella lapillus populations--even though at such a low frequency that it has gone unnoticed up to now

\section{Incidence}

DS males in our samples reach up to $13-19 \%$ (Stns 32,37 , and 52 ). These values are only a rough estimate of the actual frequency of a phenomenon as scarce as male aphally but they still suggest that DS males in Galicia are, at least, as frequent as in those sites at which the disorder has been previously noticed: frequencies in Galicia are comparable to those for Dumpton and higher than the ones for Brest.

Previous studies have observed that penis formation in DS individuals is a graded response; thus males bearing undersized penes were considered as individuals less affected by the syndrome (Gibbs 1993). Moreover, it has been argued that those less-affected individuals cause a wider variability of penis lengths in DS-affected populations (Gibbs 1993, Huet et al. 1996). As stated above, rarely have we found males bearing undersized penes in Galicia populations. Further, variability in male penis length was mostly comparable, irrespective of whether the sample had been taken at a station at which aphally had been detected or not. As Fig. 4 depicts, only 8 out of 23 samples collected at stations where female aphally was recorded reached standard deviations (SD) of male penis lengths clearly above variability estimates calculated from stations where female aphally was undetected. Besides, 5 of those 8 samples were collected at the same 2 locations (Stns 10 and 14). Thus, for the most part, penis SD was indistinguishable irrespective of whether aphally was present or not at the sampled population, and male penis-length variability seems a rather unreliable indicator for male aphally in Galician dog-whelks, at least when estimates are based on $\sim 15$ to 60 males. Likewise, our results might indicate that most DS males in our samples are only those lacking a penis whilst lessaffected individuals bearing undersized penes are too 
scarce to significantly alter the distribution of penis lengths in our samples.

\section{VDS scheme modifications}

A feature of imposex, especially in Nucella lapillus, is the variability in its expression (Oehlmann et al. 1991). Among the most conspicuous variants are some females that develop a VD but not a penis. Such variability has led to some confusion when gauging the intensity of imposex. The VDS (Gibbs et al. 1987) is among the indexes most widely applied to that characterisation. It is also the most meaningful in terms of population survival-since it is the presence of a VD that may sterilize the female. Other indices, based on penis development, lack that significance. Oddly enough, most deviations in the expression of imposex seem largely absent from United Kingdom populations (Gibbs \& Bryan 1996); it is hardly surprising that the original VDS scheme, based on dog-whelks collected on British coasts, were outlined without taking them into account. Later, Oehlmann et al. (1991) suggested an extended version of the VDS scheme determined to account for the greater variability in the expression of imposex mainly found on the north Brittany coast. This scheme has been repeatedly presented as applicable to all imposex-affected gastropod species (see, for example, Oehlmann et al. 1996) and has even attained a sort of 'official' endorsement (OSPARCOM 1997).

However, neither classification scheme satisfactorily complies with the VD development observed in Galicia populations. On the one hand, Gibbs' scheme overlooks the existence of aphallic females thus rendering their ranking troublesome, especially for low imposex stages. On the other hand, Oehlmann's classification has, in our opinion, several flaws. It is simultaneously based upon 2 different criteria: penis and VD development. Still some evidence exists suggesting that both organs might have their development controlled by separate mechanisms (Féral \& LeGall 1983) and the very existence of aphallic individuals indicates that penis and VD are not so tightly linked. Unfortunately, this mixing-up of criteria leads their scheme to assign females with an incomplete VD (e.g. their Stages 3a and $3 c$ ) to the same score as others with a fully developed one (their Stage 3b). Yet, ranking an aphallic female with a complete VD as Stage 3, while giving Stage 4 to another with a similar VD but bearing a penis seems unsound, particularly when one recalls that it is the development of the VD that causes oviduct blockage. Thus it is the presence of a VD that is significant in terms of impact and a VDS scheme should rank its development in a consistent way, irrespective of what happens with other morphological features that do not seem to affect the fertility of the female. Additionally, a key feature in Oehlmann's scheme is the unsupported proposal that sterile stages are reached only after a penis has been formed. Instead, we have found females lacking a penis but still with VD overgrowing the vulva. As already reported for other DS populations (Huet et al. 1996), we consider those females sterile, ranking them as Stage 5 to maintain their scoring in line with that for penis-bearing ones.

All the above has compelled us to modify the VDS classification by Gibbs et al. (1987) to fit our observations while still complying with some requirements. First, it should have biological significance, and our scheme is thus haced solely on ro dovolepmont, jisicgarding the use of the penis as a ranking criteria. Also, it should be applicable on a routine basis, excluding observations and techniques too cumbersome and/or time-consuming. Furthermore, the scoring should yield results comparable to those applied in previous studies. Finally, it had to be kept as simple as possible. Too complex schemes trying to score every possible variant might be unwise when dealing with a species as variable as Nucella lapillus. In fact, $N$. lapillus has been shown to be very variable in many other aspects like shell color and morphology (Moore 1936, Kitching 1977, 1985, Crothers 1985) or chromosome number (Bantock \& Cockaine 1975, Castle \& Emery 1981, Day 1990, Dixon et al. 1994). Accordingly, whether slight deviations along the development of imposex might actually reflect the presence of different paths with a genetic basis remains uncertain.

\section{Female aphally and early imposex stages}

As in the Brest area, female aphally in Galicia was more widely distributed than male aphally. However, both phenomena appear somewhat correlated: aphallic males were recorded originating only from stations with aphallic females. Moreover, the highest frequencies of aphally for both sexes coincided at Stns 37 and 52. These results agree with the view of female aphally as the defects of male DS equally manifested in the expression of imposex (Gibbs 1993). We might still remain dubious about female aphally always being the expression of DS: many locations included aphallic females but no aphallic males were found. Still, aphallic females do not show any obvious difference, irrespective of whether they have been found along with aphallic males or not. Furthermore, due to the usual low frequency of aphallic males, it is difficult to conclusively disregard their presence at a particular location. It is thus feasible that male aphally might be wider distributed than what our results suggest. 
When coexisting, female aphally was commonly more frequent than that of the male. Still our results varied greatly among sites, and frequencies at some stations were very similar for both sexes ( $\operatorname{Stn} 32)$, or even higher for males (Stn 14, although here both male and female aphally were too low for accurate estimates). Likewise, sex dependence in aphally frequency was noted at Brest and Dumpton (Gibbs 1993, Huet et al. 1996).

The most significant aspect of DS is that it may confer an advantage to dog-whelk populations exposed to TBT pollution. The best example of this beneficial role is Dumpton Gap, where DS was the only explanation to the survival of the dog-whelk population (Gibbs 1993). As stated above, VDS Stage 4 was overwhelmingly predominant among Galician dog-whelks denoting that every sampled site was exposed to a TBT pollution high enough to induce the complete development of imposex. Moreover, sterility was identified all over the region; stressing the magnitude of the exposure to the pollutant. However, some populations still presented some females showing no imposex or only an early stage. Such coexistence of 2 levels of imposex must be considered unusual (Gibbs et al. 1991). An explanation might be a decrease in ambient TBT following its partial ban. Nucella lapillus is a long-lived gastropod (surviving $>10 \mathrm{yr}$ in favourable habitats, Gibbs \& Bryan 1996) and it is possible that older individuals, exposed to higher concentrations in the past, were found thriving along with younger (but still mature) ones which have experienced only lower TBT concentrations after the ban. However, a clear link between low imposex stages and DS-affected females suggests an alternative explanation. Fig. 5 shows that the coincidence between female aphally and the presence of females non-affected by imposex (VDS

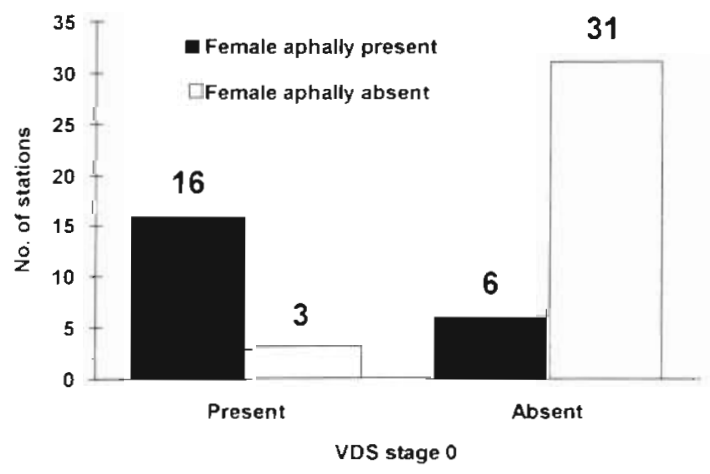

Fig. 5. Aphally and imposex in Nucella lapillus. Non-independence between presence of female aphally and presence of VDS Stage 0. Data are number of sampling stations. Female aphally present accounts for those stations with females bearing a well developed vas deferens (i.e. VDS Stages 3 to 5) but lacking a penis. $p$ value of chi-square test with Yates' correction $<0.0001$
Stage 0) is significantly higher than expected by chance (chi-square test with Yates' correction $\mathrm{p}<0.0001$ ). Out of 19 stations where VDS Stage 0 was present, 16 contained DS-affected females; whilst 31 out of the 37 sites where Stage 0 was absent, also lacked DS-females. Four out of the 6 remaining populations at which DS was present, had all females afflicted by fully developed imposex (i.e. Stages 4 to 6 ). They were located at sites where high TBT pollution might be expected, e.g. Stn 9 on the narrow mouth of a ria with 2 large shipyards, Stn 12 inside a marina, Stn 27 close to a fishing port, and Stn 39 in the immediate vicinity of a mid-sized commercial harbour. It is hardly surprising that the expected protective role of DS had failed to produce females showing no sign of imposex in those populations. Likewise, DS specimens laboratory reared at TBT concentrations $-3.8 \mathrm{ng} \mathrm{Sn} \mathrm{l}^{-1}$ failed to produce females not affected by imposex (VDS Stage 0) despite their presence in the source population; the difference being attributed to laboratory TBT levels exceeding those in the field (Gibbs 1993). Taken as a whole, our results clearly support the proposed role of DS as a TBT-resistance character (Gibbs 1993) and low imposex stages should be considered strongly linked to DS at most sites. Three stations still included females ranked as Stage 0, despite lacking DS specimens. As stated above for males, female DS is a low frequency event; we cannot completely disregard that the mutation might be present even at those places but at a frequency so low that it has gone unnoticed in our samples. On the other hand, at least 2 of those sites (Stns 8 and 46) are located outside the rias on wave-exposed shores. We have shown that TBT pollution at those sites is lower than within rias (Ruiz et al. 1998). Thus the lower exposure to TBT at those sites might have favoured the appearance of specimens less affected by imposex not necessarily linked to an increased resistance.

The percentage of females showing VDS Stages 0 to 2 at locations with presence of DS ranged from 0 to $-22 \%$. These values might be taken as an optimistic estimate of the frequency of 'TBT-resistant' females within those populations (i.e. considering all females none or slightly afflicted by imposex a result of DS traits), and more conservative estimates accounting only for females ranked as Stage 0 indicate that TBTresistant females might range from 0 to $\sim 15 \%$. The latter values are slightly lower than those recorded at Dumpton Gap (Gibbs 1993). Irrespective of the estimate employed, it is always apparent that only a moderate fraction of females seem favoured by DS against TBT pollution and that this fraction greatly varies among populations.

Also, the protective role of DS against imposex should be considered more carefully. We have found some DS females whose genital papilla was blocked by the VD (i.e. Stage 5, but aphallic) (12 specimens taken 
from Stns 14, 37, 51, and 52). As noted for the Brest area (Huet et al. 1996), these specimens might be indicative that, although aphally would signal those females with increased resistance, it does not completely immunise all of them from the sterilising effects of imposex. Furthermore, it raises the question of why should some DS females remain mostly unaffected by imposex while others do develop a full VD? Whether this variability arises from changes in environmental influences (e.g. dosage and timing of TBT exposure), or is due to DS being a graded phenomenon in females (as it seems to be in males) resulting in a range of intensities of DS expression, remains unknown. We sounded the possibility that less DS-affected females bearing an undersized penis might uncover DS as a graded anomaly in females; but as for males, variability of penis-length distribution did not meaningfully differ between samples taken where female aphally was present or absent (Fig. 4). Thus penis-length distribution in females seems of little help in discovering the presence of less DS-affected females.

\section{Is DS actually triggered by TBT pollution?}

As Dumpton and Brest are areas of high TBT contamination, it has been suggested that natural selection has increased the frequency of DS due to the fitness advantage it represents for females in those areas. It might give the impression that DS rises to detectable frequencies only where TBT pollution is high. However, the pattern of DS in Galicia casts an element of doubt about this interpretation. Here, DS appears in relatively high frequencies at sites like the ria of Betanzos, where TBT pollution cannot be considered high at least on a regional basis (for TBT values see Ruiz et al. 1998), but it is conspicuously absent from other estuar- ies more polluted by TBT (e.g. A Coruña). Obviously, TBT concentrations on most European coasts are high enough to have led to the paradoxical situation that imposex is now the rule rather than the exception. In fact, finding a dog-whelk population free from imposex seems limited to remote and isolated places (e.g. Svavarsson \& Skarphéndinsdóttir 1995). Moreover, we acknowledge that even within the ria of Betanzas, TBT exposure is high enough to have led an appreciable amount of females to sterility. However, we would like to attract attention over the possibility that DS might be not necessarily limited to severely polluted areas.

\section{How much does the presence of aphallic females affect/limit the employment of Nucella lapillus as a TBT biomonitor?}

Largely ignored is the fact that DS might affect the use of Nucella lapillus as a TBT biomonitor. The numerous examples found in the literature where $N$. lapillus has been employed to assess TBT levels in coastal environments are largely based on the assumption of a consistent response of this species to TBT. Imposex indexes (like Relative Penis Size Index [RPSI] or VDSI) appear as simple, cheap and significant biomarkers in assessing TBT effects. However, in regions like Galicia, and perhaps Brittany, where DS seems widely represented, the employment of those indexes should be carefully reconsidered. Fig. 6 illustrates the effects of DS on the performance of one of those indexes (TBT values previously published elsewhere, Ruiz et al. 1998). The relationship, RPSI versus body TBT, plotted in Fig. 6a was based on RPSI values calculated excluding aphallic individuals. The shape of the resulting relationship fits well to those published for other parts of Europe and RPSI appears as a rather accurate estimator of TBT exposure. However,
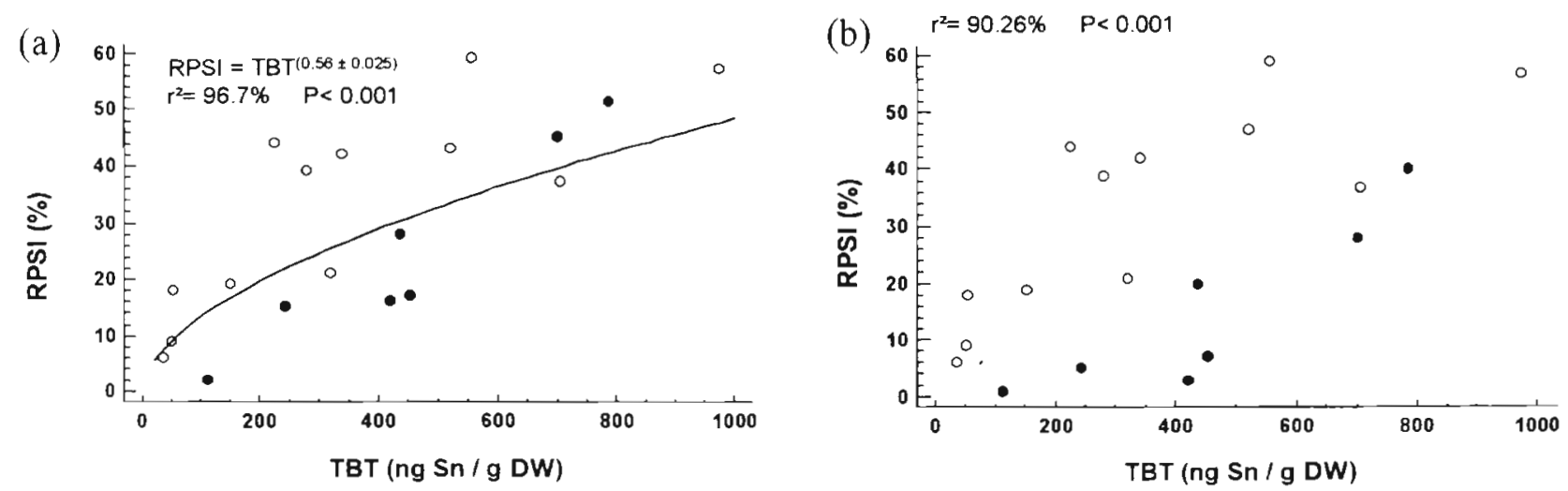

Fig. 6. Aphally and imposex in Nucella lapillus. Relationship between Relative Penis Size Index (RPSI) (\%) and tissue tributyltin (TBT) concentrations (ng Sn $\mathrm{g}^{-1}$ dry weight [DW]) when aphallic specimens were either (a) excluded or (b) included in RPSI estimates. Samples where aphally was either detected $(\bullet)$ or undetected $(0)$ 
the same relationship plotted in Fig. $6 \mathrm{~b}$ was based on RPSI values that included both DS and non-DS specimens. Clearly, the usefulness of RPSI to predict bodyTBT accumulation becomes blurred. Perhaps the main difference relays in which kind of information one is interested in. If the aim is to use RPSI as an indicator of TBT exposure, no doubt DS-affected specimens should be excluded from index estimates. However, if we are trying to assess the actual effects of imposex on dog-whelk populations, DS individuals must be qualitatively considered since their enhanced resistance is an attribute worth including in the assessment procedure. Scoring on the VDS scheme is therefore recommended.

\section{LITERATURE CITED}

Bantock CR, Cockaine WC (1975) Chromosomal polymorphism in Nucella lapillus. Heredity 34:231-245

Bryan GW, Gibbs PE (1991) Impact of low concentrations of tributyltin (TBT) on marine organisms: a review. In: Newman MC, Mclntosh AW (eds) Metal ecotoxicology: concepts and applications. Lewis Publishers, Inc, Ann Arbor FL, p 323-361

Bryan GW, Gibbs PE, Burt GR, Hummerstone LG (1987) The effects of tributyltin (TBT) accumulation on adult dogwhelks, Nucella lapillus: long-term field and laboratory experiments. J Mar Biol Assoc UK 67:525-544

Bryan GW, Gibbs PE, Burt GR (1988) A comparison of the effectiveness of tri-N-butyltin chloride and five other organotin compounds in promoting the development of imposex in the dog-whelk, Nucella lapillus. J Mar Biol Assoc UK 68:733-744

Castle SL, Emery AEH (1981) Nucella lapillus: a possible model for the study of genetic variation in natural populations. Genetica 56:11-15

Crothers JH (1985) Dog-whelks: an introduction to the biology of Nucella lapillus (L.). Field Stud 6:291-360

Day AJ (1990) Microgeographic variation in allozyme frequencies in relation to the degrees of exposure to wave action in the dogwhelk Nucella lapillus (L.) (Prosobranchia: Muriacea). Biol J Linn Soc 40:245-261

Dixon DR, Pascoe PL, Gibbs PE, Pasantes JJ (1994) Chromosomal polymorphism in Nucella. In: Beaumont AR (ed) Genetics and evolution of aquatic organisms. Chapmam \& Hall, London, p 389-398

Féral C, LeGall S (1983) The influence of a pollutant factor (tributyltin) on the neuroendocrine mechanism responsible for the occurrence of a penis in the females of Ocenebra erinacea. In: Lever J, Boer $\mathrm{H}$ (eds) Molluscan neuroendocrinology. Proceedings of the International Minisymposium on Molluscan Endocrinology, (1982) North Holland Publishing Company, Amsterdam p 173-175

Fioroni P, Oehlmann J, Stroben E (1991) The pseudohermaphroditism of prosobranchs: morphological aspects. Zool Anz 226:1-26

Gibbs PE (1993) A male genital defect in the dog-whelk, Nucella lapillus (Neogastropoda), favouring survival in a TBT-polluted area. J Mar Biol Assoc UK 73:667-678

Gibbs PE, Bryan GW (1994) Biomonitoring of tributyltin (TBT) pollution using the imposex response of neogastropod molluscs. In: Kramer KJM (ed) Biomonitoring of coastal waters and estuaries. CRC Press, Inc, Boca Raton, p 205-226
Gibbs PE, Bryan GW (1996) TBT-induced imposex in neogastropod snails: masculinization to mass extinction. In: de Mora SJ (ed) Cambridge environmental chemistry series, 8: Tributyltin: case study of an environmental contaminant. Cambridge University Press, Cambridge, p 212-236

Gibbs PE, Bryan GW, Pascoe PL. Burt GR (1987) The use of the dog-whelk, Nucella lapillus, as an indicator of tributyltin (TBT) contamination. J Mar Biol Assoc UK 67 . $507-523$

Gibbs PE, Pascoe PL, Burt GR (1988) Sex change in the female dog-whelk, Nucella lapillus, induced by tributyltin from antifouling paints. J Mar Biol Assoc UK 68:715-731

Gibbs PE, Bryan GW, Pascoe PL (1991) TBT-induced imposex in the dogwhelk, Nucella lapillus: geographical uniformity of the response and effects. Mar Environ Res 32:79-87

Gibbs PE, Bebianno MJ, Coelho MR (1997) Evidence of the differential sensitivity of neogastropods to tributyltin (TBT) pollution, with notes on a species (Columbella rustica) lacking the imposex response. Environ Technol 18: $1219-1224$

Huet M, Paulet YM, Le Pennec M (1996) Survival of Nucella lapillus in a tributyltin-polluted area in west Brittany: a further example of a male genital defect (Dumpton syndrome) favouring survival. Mar Biol 125:543-549

Kitching JA (1977) Shell form and niche occupation in Nucella lapillus (L.) (Gastropoda). J Exp Mar Biol Ecol 26: $275-287$

Kitching JA (1985) The ecological significance and control of shell variability in dogwhelks from temperate rocky shores. In: Moore PG, Seed R (eds) The ecology of rocky coasts. Hodder \& Stoughton, London, p 234-248

Mensink BP, van Hattum B, ten Hallers-Tjabbes CC, Everaarts JM, Kralt H, Vethaak AD, Boon JP (1997) Tributyltin causes imposex in the common whelk Buccinum undatum: mechanism and occurrence. Netherlands Institute for Sea Research, Texel, NIOZ-Rapport 1997-6

Moore HB (1936) The biology of Purpura lapillus. I. Shell variation in relation to environment. J Mar Biol Assoc UK 21 $61-89$

Oberdörster E, Rittschof D, McClellan-Green P (1998) Testosterone metabolism in imposex and normal Ilyanassa obsoleta: comparison of field and TBTA CI-induced imposex. Mar Pollut Bull 36:144-1.51

Oehlmann J, Bettin C (1996) TBT-induced imposex and the role of steroids in marine snails. Malacol Rev Suppl. 6: (Molluscan Reproduction): 157-161

Oehlmann J, Stroben E, Fioroni P (1991) The morphological expression of imposex in Nucella lapillus (Linnaeus) (Gastropoda: Muricidae). J Molluscan Stud 57:375-390

Oehlmann J, Stroben E, Fioroni P (1996) New facts about TBT-induced imposex in prosobranchs: general aspects. Malacol Rev Suppl (Mollusc Reprod) 6:149-155

OSPARCOM (1997) JAMP guidelines for the contaminantspecific biological effects monitoring. Technical Annex 3. TBT-specific biological effects monitoring. Joint Assess ment and Monitoring Programme, London

QUASIMEME Scientific Assessment Group (1998) QUASIMEME II. International laboratory performance studies. Round 12. Exercise $359 \mathrm{BE}-1$ Imposex and intersex in marine snails. QUASIMEME Project Office, Aberdeen

Ruiz JM, Quintela M, Barreiro R (1998) Ubiquitous imposex and organotin bioaccumulation in gastropods Nucella lapillus from Galicia (NW Spain): a possible effect of nearshore shipping. Mar Ecol Prog Ser 164:237-244

Svavarsson J, Skarphéndinsdóttir $H$ (1995) Imposex in the dogwhelk Nucella lapillus (L.) in Icelandic waters. Sarsia $80: 35-40$ 